\title{
Yellow deposits formation in roots is a part of tobacco plant phenotype under sulfur deficiency
}

\author{
GRZEGORZ MONIUSZKO \\ KATARZYNA ZIENTARA-RYTTER \\ Institute of Biochemistry and Biophysics, \\ Polish Academy of Sciences \\ ul. Pawinskiego 5A, 02-106 Warsaw, Poland

\section{Correspondence: \\ Grzegorz Moniuszko \\ e-mail: Mongr@ibb.waw.pl \\ Institute of Biochemistry and Biophysics, \\ Polish Academy of Sciences \\ ul. Pawinskiego 5A, 02-106 Warsaw, Poland}

Key words: sulfur deficiency; UV absorbing compounds; yellow root; root color; Nicotiana tabacum
Received October 10, 2014.

Revised April 21, 2015.

Accepted April 27, 2015.

\begin{abstract}
Background and Purpose: It is known that plants respond to sulfur (S) deficit by adapting their physiology and development. Nowadays, scientists concentrate on the cellular level of such response, studying molecular processes, often treating visual phenotypes as fully explored and obvious. The goal of this study was to challenge such believes and find a new visual phenotype of plants during their response to $S$ deficit.
\end{abstract}

Materials and Methods: The macroscopic and microscopic observation of Nicotiana tabacum plants grown under sulfur deficiency or control condition was conducted. Additionally, the absorbance spectrum of ethanol extracts from plant roots was measured.

Results and Conclusions: In this study we showed that root color changes from colorless to yellow after transfer to $S$ deficiency conditions. Microscopic observation of yellow roots showed that their color is a result of the yellowish deposits formation inside the root epidermis cells. Next experiments allowed to narrow down the list of chemicals responsible for the observed root phenotype to UV absorbing compounds. Our results, taken together with the data available in literature, pointed to the phenolic compounds as the most probable component of yellowish deposits responsible for change of root color during plant response to $S$ deficiency. The physiological role of such accumulation is yet to be determined.

\section{INTRODUCTION}

T is known that plants respond to nutrient deficit by adapting their 1 physiology and development [reviewed in: (1-3)]. The initial discovered and reported nutrient deficiency symptoms were macroscopic (eyevisible) changes, however soon after that, researchers realized that changes on cellular level provide more detailed data. Nowadays, scientists concentrate on the studying of molecular processes. Similar trend could be observed in the area of research of plant response to sulfur (S) deficit. Review articles from the last decade often did not even mention any visual phenotypes treating them as obvious and out of date.

Indeed, no new spectacular, visible phenotypes of plants grown in $S$ deficiency conditions were reported recently, however this might be the result of not looking particularly for them. The second possibility is the existence of an issue with repeatability and specificity of visible symptoms. Despite of mentioned problems, chlorosis, necrosis, leaves folding, color changes and other deficit indicators, which are mostly leaf oriented, are well described, even when difficult to relate to particular 
nutrient. The classic symptom of S deficit in plants is chlorosis, which concerns mainly young leaves. The leaves also often have folded edges, which is especially visible in plants with a high demand for $S$, such as Brassica napus, B. napobrassica and B. rapa. Under S-deficient conditions plants grow more slowly and are smaller. Sometimes (especially in an abundance of $\mathrm{N}$ supply) a red-violet color may be observed on leaves in the places of vascular tissues. After prolonged deficit leaves become brittle and fragile (and may even crumble) These characteristic symptoms, described in plant physiology books (4-6), mainly concern shoots.

On the other hand, studies on the roots are still well behind due to the concentration of work on leaves for the last few centuries (7). Root study has accelerated recently yet under the $S$ deficiency only two macroscopic changes in root organ were reported previously: changes in root length $(8,9)$ and its architecture (9).

In this work a new visual phenotype, namely formation of yellow deposits in roots of tobacco (Nicotiana tabacum) plants in response to $S$ deficiency is described.

\section{MATERIAL AND METHODS}

\section{Plant material and growing conditions}

In this study the $N$. tabacum cv. LA Burley 21 (10) was the source of plant material. For tobacco plant cultures $\mathrm{AB}$ and Hoagland media, either full (nS) or lacking sulfur (S-), prepared according to previously described protocols $(11,12)$, were used. Tobacco seeds were surface sterilized before germination. All plants were grown in growth chamber under the conditions of $60 \%$ relative humidity, with a day/night regime of $16 \mathrm{~h}$ light $300 \mu \mathrm{mol}$ photons $\mathrm{m} 2-1 \mathrm{~s}-1$ at $23^{\circ} \mathrm{C}$ and $8 \mathrm{~h}$ dark at $19^{\circ} \mathrm{C}$. For experiments on seedlings $0.5 \mathrm{x} \mathrm{AB}$ and $0.5 \mathrm{x}$ Hoagland media were used, in the case of cultures on Petri dishes solidified with $0.8 \%$ (v/w) ultrapure agarose (Invitrogen). The 12 to 18-day-old seedlings were used for transfer onto new media ( $\mathrm{nS}$ or $\mathrm{S}-$ ), prior to the further experiments. For experiments on larger plants the hydroponic cultures using $\mathrm{AB}$ and Hoagland media (with changing after 2 weeks and next every single week) were prepared. The 4 to 8 -week plants were used for transfer onto new media (nS or $\mathrm{S}$-).

\section{Starch staining}

For starch identification the iodine staining was done [using modified protocol after (13)]. Plant roots were stained with Lugol's iodine solution (6 mM iodine, 43 $\mathrm{mM} \mathrm{KI}$, and $0.2 \mathrm{~N} \mathrm{HCl}$ ) using under-pressure, created with a syringe, for better penetration. Before observations, excess of staining solution was removed by rinse, three to five times, with water.

\section{Microscope observations}

The images were obtained at the Laboratory of Confocal and Fluorescence Microscopy at IBB PAS with a Nicon confocal microscope, Eclipse TE2000-E and processed using EZ-C1 3.60 FreeViewer software.

\section{Preparing ethanol extract from plant roots and measurement of the absorbance spectrum}

The $100 \mathrm{mg}$ of roots of 20-day-old seedlings, growing for last 5 days on either $0.5 \mathrm{AB}-\mathrm{S}$ or $0.5 \mathrm{ABnS}$ medium was collected to the sterile Eppendorf tube. The ethanol extracts of collected tissues were prepared according to the available protocol (14). The material has been macerated in $500 \mu \mathrm{l}$ of $96 \%$ ethanol using micro pestle, then vortexed and heated in $70^{\circ} \mathrm{C}$ for 15 minutes with shaking. After 5 min centrifugation at $10000 \mathrm{rpm}$ the supernatant has been transferred to fresh Eppendorf tube. Then, the procedure has been repeated using pellet as a material and the supernatant has been added to the supernatant collected before. Right after that the samples absorbance were measures using the Cary $50 \mathrm{UV}-\mathrm{V}$ is spectrophotometer (Varian Inc.), in the wavelength range from $200 \mathrm{~nm}$ to $800 \mathrm{~nm}$, using a built in function of the equipment.

\section{RESULTS}

\section{Changes of roots color after transfer of plants to sulfur deficiency conditions}

Changes in visual plant phenotype were investigated during response to $S$ deficiency, using plants germinated and cultivated on full media and then transferred to media with limited $S$ availability. Apart from the already reported effect in root length (15) roots of the tobacco plants were yellowing under $S$ deficiency (S-) but stayed colorless under control condition (nS) (Fig. 1a). The observed effect started to be visible 3-5 days after plant transfer to the $S$ - condition and was reversible. Transfer of the plants back to sufficient medium caused in remove of the yellow color from roots, unless plants were growing under S- conditions for too long. Prolonged S deficiency stress, starting from 8th to 12th day, resulted in root color change to pale brown, which was irreversible. It is noteworthy that these effects were consistently observed on seedlings grown on the solid or in liquid media as well as on the older plants cultivated hydroponically. Moreover, root yellowing was not related to the specific medium as using two different types of media, namely $A B$ and Hoagland, gave the same results. To further study the nature of this effect of $S$ deprivation, the yellow roots were used as a material for microscope observation. 


\section{Color deposits existence in roots during plant response to sulfur deficiency}

Examination of tobacco yellow roots under the microscope revealed the existence of color, yellowish, deposits inside the cells of the root epidermis. For the best clarity the root hairs are shown (Fig. 1b), however deposits were presented in other cells of epidermis as well. Deposits did not have any regular structure, what suggested that they were not made of starch.
Tobacco belongs to the Solanaceae family which accumulate starch, usually as a starch grains, in different plant organs. Therefore, it was crucial to exclude possibility that deposits, observed during plant response to $S$ deficit, contained starch as a main component. Observations of iodine stained roots, both by eye and under the microscope, showed no difference between roots of the plants grown in $\mathrm{nS}$ and $\mathrm{S}$ - conditions. After elimination of starch, possibility of occurrence of other compounds in the yellow deposits was considered.

a

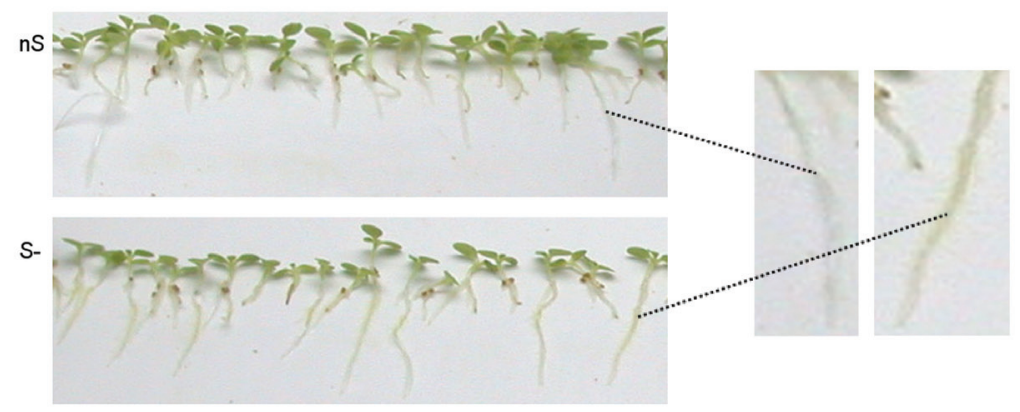

b
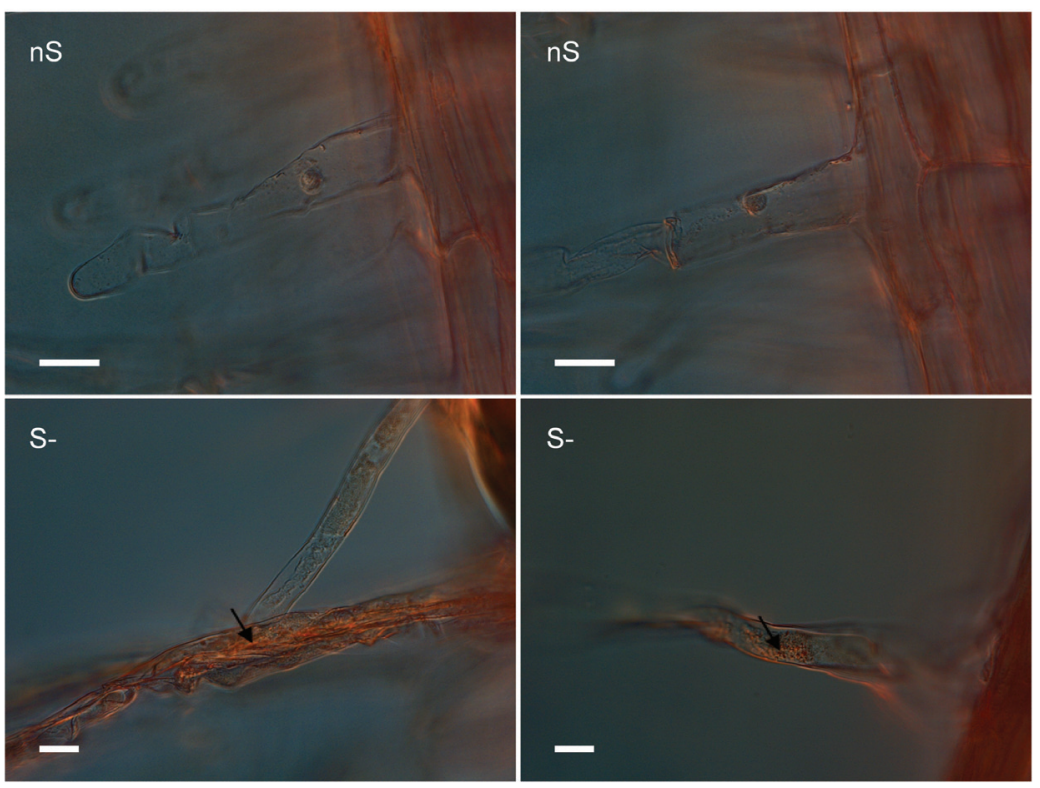

C

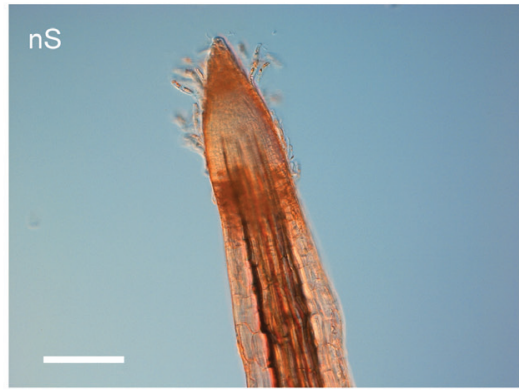

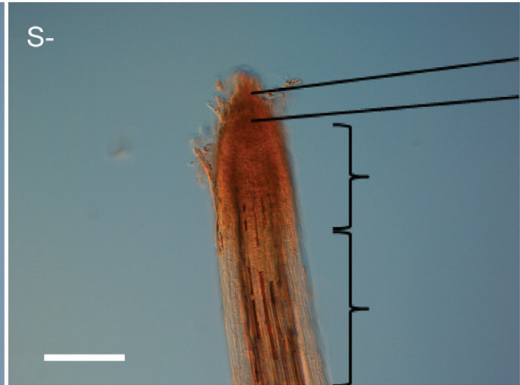

Root Cap

Apical Meristem

Zone of Cell Division

Zone of Cell Elongation

Figure 1. Root phenotype during plant response to sulfur (S) deficiency.

$a$-root yellowing in response to $S$ deficiency, $b$ - arrows indicate deposits accumulation inside root hairs during plant response to $S$ deficiency (on left 0.5 Hoagland medium, on right $0.5 \mathrm{AB}$ medium), $c$ - changes of root tip appearance during plant response to $S$ deficiency. The 20-day-old tobacco seedlings, 5 days after transfer to new media are presented. (S-) - S deficiency, (nS) - optimal sulfur supply / control condition, Scale bars: b-10 $\mu \mathrm{m}, c 100 \mu \mathrm{m}$. 

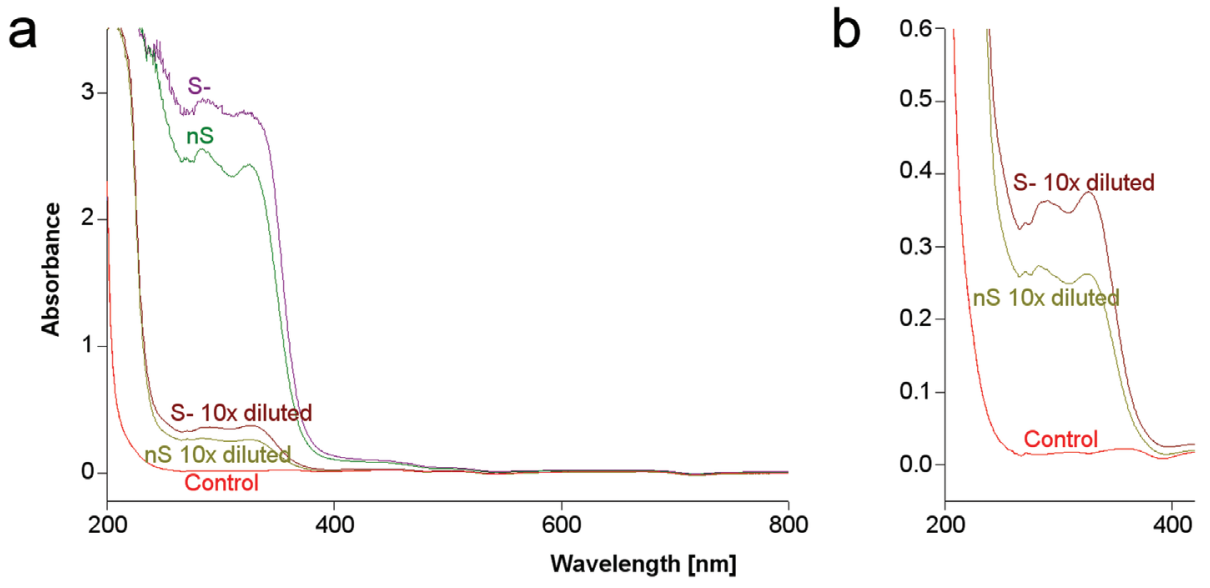

Figure 2. Absorbance spectra of ethanol extracts of roots of plants growth under different sulfur (S) supplies.

$a$ - comparison of concentrated and diluted samples, $b$ - crop of spectra for samples 10 times diluted with water. Material was collected from 20-day-old tobacco seedlings, 5 days after transfer to new media (nS or $S$-). (S-) - S deficiency, (nS) - optimal sulfur supply / control condition.

The ethanol extracts from the yellow, as well as from the control roots, were prepared as described in the Material and Methods. The difference in the color of the extracts from the roots of S-sufficient and S-deficient plants was eye-visible. Subsequently, the absorption spectra were measured at a wavelength of 200-800 $\mathrm{nm}$. The obtained spectra (Fig. 2a) showed the difference between $\mathrm{nS}$ and $S$ - root extracts in the wavelength range between 250 and 400. It is noteworthy that absorbance higher than 1 might negatively influence the accuracy of the results. The same measurement repeated in the 10-fold diluted extracts (Fig. $2 \mathrm{~b})$ not only confirmed the higher absorbance in range of 250-400 $\mathrm{nm}$ of the extract made from the roots of plants grown under $\mathrm{S}$ deficit, but also highlighted some subtle changes. Both spectra had the peaks at 270, 285 and 325 $\mathrm{nm}$, however the ratio of the two latter peaks were different. The $285-\mathrm{nm}$ peak was higher than the $325-\mathrm{nm}$ one in $\mathrm{nS}$ condition but lower under $\mathrm{S}$ deficit.

\section{Root tip phenotype changes in plant response to sulfur deficiency}

During microscope analysis of the roots more phenomena were found, however only one of them was consistently observed. The appearance of the root tip was different for roots grown in $\mathrm{nS}$ condition than those growing under $S$ - (Fig. 1c). The exact tip of the root of plants grown in S- condition was yellowish. Yellow color area contained the Root Cap as well as Apical Meristem and Zone of Cell Division while majority of the cells of Zone of Cell Elongation remained almost colorless (except cells close to the border with Zone of Cell Division which were yellow). In contrast, in the root of the plants grown under $\mathrm{nS}$ condition, the Root Cap was yellow as well as the elongation zone cells localized near the border between Zone of Cell Division and Zone of Cell Elongation. In this case the Apical Meristem and Zone of Cell Division stayed colorless.

\section{DISCusSION}

\section{Root yellowing is a part of plant response to sulfur deficiency}

New phenotype of plants roots in response to $S$ deficiency was shown in this study. Our results demonstrate that change of roots color from colorless to yellow (visible after 3-5 days of seedling growth in S-) is a part of plant response to $S$ deficit. Similar observations have been confirmed in personal communications on the $2^{\text {nd }}$ Sulphyton Conference, however the specificity and repeatability of the phenomenon has been unstudied and unknown. On the other hand, the cadmium (Cd) stress results in high demand for $S$ metabolites (16) thus is similar to $S$ deficiency stress. In some studies, the change of root color (to brownish) in Arabidopsis thaliana and Cicer arietinum response to $\mathrm{Cd}$ has been reported $(17,18)$. In the other studies (on Oryza sativa and Merwilla plumbea) the color change to yellowish is visible on figures but the phenomenon is not discussed within the papers $(19,20)$.

Prolonged $S$ deficit resulted in change of the color of the root from yellow to pale brown (visible after 8-12 days of $\mathrm{S}$-). Our data suggest that turning into pale brown is probably a result of cell death because only yellow color could be fully inverted to the transparent by transfer of the plants back to the $S$-sufficient medium. Such observation may be a suggestion that the death of the plant root cells start 8-12 days after transfer to $S$ deficit. This may explain the phenomenon of different response of plants (reported for $A$. thaliana and $N$. tabacum) to various stringency of $S$ deficit. Under the very strict $S$ starvation the root length increase in response to stress condition was not observed (21), while such kind of response exists under less severe $S$ shortage $(8,9,15)$. Our results taken together with the mentioned data indicate that the lack of root length increase might be a derivative of the death of the root cells. It is known that 
during late phase of plant response to $S$ deficit the switch from root system expansion to reproduction strategy occurs $(2,22,23)$. One of the possibilities of root growth inhibition is programmed death of root cells. Therefore, maybe the changes of the root color could be treated as an indicator of the late phase of plant response to $S$ deficiency. Such hypothesis is especially tempting as we showed the changes of root tip phenotype in response to $S$ deficit (manifested visually by change of color of the root tip). We do not know yet how this influence the activity of Apical Meristem, therefore more research is needed to clarify such issue.

\section{Nature of root yellowing during plant response to $\mathbf{S}$ deficiency}

Microscopic observation showed that yellowing of roots is a result of the yellowish deposits formation inside the root cells. Such effect has not been reported previously, therefore we decided to perform experiments that allowed to narrow down the list of the most possible building material of the observed deposits. Our data showed that starch is not the main compound of the observed speckles. Such observance corresponds with the other study (covering more stresses) in which the starch grains accumulation in roots were not detected during $A$. thaliana response to $S$ deficit (24). On the other hand, comparison of the absorbance spectra of the ethanol extracts from the roots showed difference between $\mathrm{nS}$ and $\mathrm{S}$ - in the wavelength range between $250 \mathrm{~nm}$ and $400 \mathrm{~nm}$ (which is mainly within UV range, however it overlaps visible light spectra). Such alteration, taken together with the eye-visible color difference, between the ethanol extracts analyzed in the experiments, point to the UV absorbing compounds (UVAC) as a reason of yellow color. The most abundant group of such molecules, reported as responsible for most of the changes of extract spectra in UV range are phenolic compounds $(25,26)$. Noteworthy, phenolics (mostly the subgroup called flavonoids) are, besides chlorophylls, the main group of compounds that affect color of plant organs. Moreover, it was shown that the level of phenolic compounds change during plant response to environmental stresses (27) including deficits of such nutrients as iron $(\mathrm{Fe})(28)$, phosphorus (P) (29), nitrogen (N) (30) and S (31). Unfortunately, studies that showed increased level of flavonoids under $S$ deficit were performed using whole seedlings as plant material. On the other hand, studies on roots of plants grown under Fe deficit may be useful as recently, the co-expression of Arabidopsis genes encoding S-adenosylomethionine synthetase 1 (SAM1, TAIR: AT1G02500), Phe ammonia lyase 1 (PAL1, TAIR: AT2G37040), Phe ammonia lyase 2 (PAL2, TAIR: AT3G53260) and CoA ligase (4CL1, TAIR: AT1G51680), according to 300 rootrelated microarray experiments, was shown (32). PALs catalyze the initiation, while 4CLs mediate the last step, of the general phenylpropanoid pathway. Moreover the expression of two different SAMs (TAIR: AT3G17390, AT4G01850) were found to be up-regulated during $S$ deficit (33). Other study (34) reported only one SAM
(TAIR: AT3G17390) as up-regulated in shoot and another (TAIR: AT2G36880) as down-regulated in roots. On the other hand in both $S$ deficiency studies (one with whole seedlings and one with only roots as a plant material) available through Genevestigator software (35) the level of all four genes, mentioned previously as co-expressed, remained stable, independently of $S$ status. This seems to be in contrary to the researches that pointed to the up- or down-regulation of $S A M s$ during $S$ deficit, however different $S A M s$ may not be regulated on the same way. Noteworthy, the mentioned four genes reached the higher level of expression in root-related experiment, which suggests that they are constitutively expressed on relatively high level in roots. Therefore, biosynthesis of phenolic compounds may be not regulated mainly on the transcription level during $S$ deficiency. On the other hand the lack of regulation on the level of whole organ does not prove the same concept on the tissue level. The UPBEAT1 (UPB1, TAIR: At2g47270) has been lately connected, using the knockout Arabidopsis plants, with phenylpropanoid biosynthesis due to the regulation of transcription of two PALs and two 4CLs (36). Recently it has been shown that UPB1 localizes within the root tip in the identical way (under control and $S$ deficiency conditions) as the yellow color on Fig.1c (37). Such observation supports the hypothesis of phenolic compounds involvement in the development of the roots yellow color during $S$ deficiency.

Taking together the results from this work it is clear that yellowing of roots is a part of plant response to $S$ deficiency. The reason of such phenotype is a formation of color deposits inside root cells. According to the results presented in this study and data available in the literature, the nature of this speckles is probably related to the phenolics, however further analyses are needed to fully clarify that.

Acknowledgments: The authors gratefully acknowledge Professor Agnieszka Sirko (Institute of Biochemistry and Biophysics, Polish Academy of Sciences) for the useful discussion. This work was supported by the Polish Ministry of Science and Higher Education (grant Nr N N302 119435).

\section{REFERENCES}

1. DAVIDIAN JC, KOPRIVA S 2010 Regulation of sulfate uptake and assimilation--the same or not the same? Mol Plant 3: 314-25 http:// dx.doi.org/10.1093/mp/ssq001

2. LEWANDOWSKA M, SIRKO A 2008 Recent advances in understanding plant response to sulfur-deficiency stress. Acta Biochim Pol 55: 457-71 http://www.actabp.pl/pdf/3_2008/457.pdf

3. TAKAHASHI H, KOPRIVA S, GIORDANO M, SAITO K, HELL R 2011 Sulfur assimilation in photosynthetic organisms: molecular functions and regulations of transporters and assimilatory enzymes. Annu Rev Plant Biol 62:157-84 http://dx.doi. org/10.1146/annurev-arplant-042110-103921

4. STARCK Z 2002 in Kopcewicz J, Lewak S (eds). Fizjol. Roślin. Wydawnictwo Naukowe PWN, p228-239

5. SIUTA J, REJMAN-CZAJKOWSKI M 1980 Siarka w biosferze: praca zbiorowa. Panstwowe Wydawnictwo Rolnicze i Lesne PWRiL. 
6. THE SULPHUR INSTITUTE 2007 S deficiency symptom. http://www.sulphurindia.com/

7. SILBERBUSH M 2013 Root Study: Why Is It behind Other Plant Studies? American Journal of Plant Sciences 4:197-202 http://dx.doi. org/10.4236/ajps.2013.42026

8. BOURANIS DL, CHORIANOPOULOU SN, KOLLIAS C, MANIOU P, PROTONOTARIOS VE, SIYIANNIS VF, et al. 2006 Dynamics of Aerenchyma Distribution in the Cortex of Sulfate-deprived Adventitious Roots of Maize. Ann Bot 97: 695704 http://dx.doi.org/10.1093/aob/mcl024

9. KUTZA, MULLERA, HENNIG P, KAISER WM, PIOTROWSKI M, WEILER EW $2002 \mathrm{~A}$ role for nitrilase 3 in the regulation of root morphology in sulphur-starving Arabidopsis thaliana. Plant $J$ 30: 95-106 http://dx.doi.org/10.1046/j.1365-313X.2002.01271.x

10. LEGG PD, COLLINS GB, LITTON CC 1970 Registration Of LA Burley 21 Tobacco Germplasm. Crop Sci 10: 212 http://dx.doi. org/10.2135/cropsci1970.0011183X001000020041x

11. WAWRZYNSKA A, LEWANDOWSKA M, HAWKESFORD MJ, SIRKO A 2005 Using a suppression subtractive library-based approach to identify tobacco genes regulated in response to shortterm sulphur deficit. J Exp Bot 56: 1575-1590 http://dx.doi. org/10.1093/jxb/eri152

12. ZIENTARA-RYTTER K, LUKOMSKA J, MONIUSZKO G, GWOZDECKI R, SUROWIECKI P, LEWANDOWSKA M, et al. 2011 Identification and functional analysis of Joka2, a tobacco member of the family of selective autophagy cargo receptors. Autophagy 7: 1145-58 http://dx.doi.org/10.4161/auto.7.10.16617

13. CASPAR T, LIN TP, KAKEFUDA G, BENBOW L, PREISS J, SOMERVILLE C 1991 Mutants of Arabidopsis with altered regulation of starch degradation. Plant Physiol 95: 1181-8 http://dx.doi. org/10.1104/pp.95.4.1181

14. LICHTENTHALER HK, WELLBURN AR 1983 Determinations of total carotenoids and chlorophylls a and b of leaf extracts in different solvents. Biochem Soc Trans 11: 591-592 http://dx.doi. org/10.1042/bst0110591

15. LEWANDOWSKA M, WAWRZYNSKA A, MONIUSZKO G, LUKOMSKA J, ZIENTARA K, PIECHO M, et al. 2010 A contribution to identification of novel regulators of plant response to sulfur deficiency: Characteristics of a tobacco gene UP9C, its protein product and the effects of UP9C silencing. Mol Plant 3: 347$60 \mathrm{http}: / / \mathrm{dx}$.doi.org/10.1093/mp/ssq007

16. VIEHWEGER K 2014 How plants cope with heavy metals. Bot Studies 55: 35 http://dx.doi.org/10.1186/1999-3110-55-35

17. SUZUKI N 2005 Alleviation by calcium of cadmium-induced root growth inhibition in Arabidopsis seedlings. Plant Biotechnol 22: 19-25 http://dx.doi.org/10.5511/plantbiotechnology.22.19

18. MONDAL NK, DAS C, ROY S, BANERJEE A 2013 Effect of Varying Cadmium Stress on Chickpea (Cicer arietinum L) Seedlings: An Ultrastructural Study. Annals of Environmental Science 7: 59-70 http://iris.lib.neu.edu/cgi/viewcontent.cgi?article=1123\& context=aes

19. LUX A, VACULÍK M, MARTINKA M, LISKOVÁ D, KULKARNI MG, STIRK WA, et al. 2011 Cadmium induces hypodermal periderm formation in the roots of the monocotyledonous medicinal plant Merwilla plumbea. Ann Bot 107: 285-92 http://dx.doi.org/10.1093/aob/mcq240

20. LIU CH, CHAO YY, KAO CH 2013 Effect of potassium deficiency on antioxidant status and cadmium toxicity in rice seedlings. Bot Studies 54: 2 http://dx.doi.org/10.1186/1999-3110-54-2

21. WU Y, ZHAO Q, GAO L, YU XM, FANG P, OLIVER DJ, et al. 2010 Isolation and characterization of low-sulphur-tolerant mutants of Arabidopsis. J Exp Bot 61: 3407-22 http://dx.doi.org/10.1093/ jxb/erq161

22. HAWKESWORD MJ, DE KOK LJ 2006 Managing sulphur metabolism in plants. Plant Cell Environ 29: 382-395 http://dx.doi. org/10.1111/j.1365-3040.2005.01470.x

23. HOEFGEN R, NIKIFOROVA VJ 2008 Metabolomics integrated with transcriptomics: assessing systems response to sulfur-deficien- cy stress. Physiol Plant 132: 190-198 http://dx.doi.org/10.1111/ j.1399-3054.2007.01012.x

24. IYER-PASCUZZI AS, JACKSON T, CUI H, PETRICKA JJ, BUSCH W, TSUKAGOSHI H, et al. 2011 Cell identity regulators link development and stress responses in the Arabidopsis root. Dev Cell 21: 770-82 http://dx.doi.org/10.1016/j.devcel.2011.09.009

25. BIALONSKA D, ZOBEL A, KURAS M, TYKARSKA T, SAWICKA-KAPUSTA K 2007 Phenolic compounds and cell structure in bilberry leaves affected by emission from a $\mathrm{Zn}-\mathrm{Pb}$ smelter. Water Air Soil Pollut 181: 123-133 http://dx.doi.org/10.1007/ s11270-006-9284-x

26. SZAFRANSKA K, GLINSKA S, JANAS KM 2012 Changes in the nature of phenolic deposits after re-warming as a result of melatonin pre-sowing treatment of Vigna radiata seeds. J Plant Physiol 169: 34-40 http://dx.doi.org/10.1016/j.jplph.2011.08.011

27. DIXON RA, PAIVA NL 1995 Stress-Induced Phenylpropanoid Metabolism. Plant Cell 7: 1085-1097 http://dx.doi.org/10.1105/ tpc.7.7.1085

28. JIN CW, YOU GY, HE YF, TANG C, WU P, ZHENG SJ 2007 Iron Deficiency-Induced Secretion of Phenolics Facilitates the Reutilization of Root Apoplastic Iron in Red Clover. Plant Physiol 144: 278-285 http://dx.doi.org/10.1104/pp.107.095794

29. WAGATSUMA T, ISHIKAWA S, AKIMOTO T, TAWARAYA K, OFEI-MANU P 2002 Mechanisms of higher tolerance of Al stress in phosphorus deficient maize seedlings: The significance of phenolics in Al resistance. In: Horst WJ, Schenk MK, Bürkert A, Claassen N, Flessa H, Frommer WB, et al. (eds) Plant Nutrition (Developments in Plant and Soil Sciences; vol. 92). Springer, Netherlands, p454 http://dx.doi.org/10.1007/0-306-47624-X_219

30. LOVDAL T, OLSEN KM, SLIMESTAD R, VERHEUL M, LILLO C 2010 Synergetic effects of nitrogen depletion, temperature, and light on the content of phenolic compounds and gene expression in leaves of tomato. Phytochemistry 71: 605-613 http:// dx.doi.org/10.1016/j.phytochem.2009.12.014

31. NIKIFOROVA VJ, KOPKA J, TOLSTIKOV V, FIEHN O, HOPKINS L, HAWKESFORD MJ, et al. 2005 Systems Rebalancing of Metabolism in Response to Sulfur Deprivation, as Revealed by Metabolome Analysis of Arabidopsis Plants. Plant Physiol 138: 304-318 http://dx.doi.org/10.1104/pp.104.053793

32. YANG TJ, LIN WD, SCHMIDT W 2010 Transcriptional Profiling of the Arabidopsis Iron Deficiency Response Reveals Conserved Transition Metal Homeostasis Networks. Plant Physiol 152: 2130 2141 http://dx.doi.org/10.1104/pp.109.152728

33. NIKIFOROVA V, FREITAG J, KEMPA S, ADAMIK M, HESSE H, HOEFGEN R 2003 Transcriptome analysis of sulfur depletion in Arabidopsis thaliana: interlacing of biosynthetic pathways provides response specificity. Plant J 33: 633-650 http://dx.doi. org/10.1046/j.1365-313X.2003.01657.x

34. HIRAI MY, FUJIWARA T, AWAZUHARA M, KIMURA T, NOJI M, SAITO K 2003 Global expression profiling of sulfurstarved Arabidopsis by DNA macroarray reveals the role of Oacetyl-1-serine as a general regulator of gene expression in response to sulfur nutrition. Plant J 33: 651-63 http://dx.doi.org/10.1046/j. 1365-313X.2003.01658.x

35. HRUZ T, LAULE O, SZABO G, WESSENDORP F, BLEULER S, OERTLE L, et al. 2008 Genevestigator V3: A Reference Expression Database for the Meta-Analysis of Transcriptomes. Adv Bioinformatics $2008420747 \mathrm{http} / / / \mathrm{dx}$.doi.org/10.1155/2008/420747

36. TSUKAGOSHI H, BUSCH W, BENFEY PN 2010 Transcriptional regulation of ROS controls transition from proliferation to differentiation in the root. Cell. 143: 606-16 http://dx.doi. org/10.1016/j.cell.2010.10.020

37. Busch W, Moore BT, Martsberger B, Mace DL, Twigg RW, Jung J, et al. 2012 A microfluidic device and computational platform for high-throughput live imaging of gene expression. Nat Methods 9: 1101-6 http://dx.doi.org/10.1038/nmeth.2185 